This item was submitted to Loughborough's Research Repository by the author.

Items in Figshare are protected by copyright, with all rights reserved, unless otherwise indicated.

\title{
The effect of including a fetus in the uterus model on the risk of fetus mortality through drop test and frontal crash simulations
}

\section{PLEASE CITE THE PUBLISHED VERSION}

http://dx.doi.org/10.1080/13588265.2016.1166707

\section{PUBLISHER}

(C) Taylor \& Francis

\section{VERSION}

AM (Accepted Manuscript)

\section{PUBLISHER STATEMENT}

This work is made available according to the conditions of the Creative Commons Attribution-NonCommercialNoDerivatives 4.0 International (CC BY-NC-ND 4.0) licence. Full details of this licence are available at: https://creativecommons.org/licenses/by-nc-nd/4.0/

\section{LICENCE}

CC BY-NC-ND 4.0

\section{REPOSITORY RECORD}

Acar, Serpil, M. Meric, and Memis Acar. 2016. "The Effect of Including a Fetus in the Uterus Model on the Risk of Fetus Mortality Through Drop Test and Frontal Crash Simulations”. Loughborough University. https://hdl.handle.net/2134/21836. 


\title{
The effect of including a fetus in the uterus model on the risk of fetus mortality through drop test and frontal crash simulations
}

\author{
B. S. Acar, M. Meric and M. Acar \\ Loughborough University, Loughborough, UK
}

\begin{abstract}
Computational modelling is an effective way of estimating the risk of injuries and fatalities in road traffic accidents. Computational pregnant occupant modelling has an additional important role in the investigation of the risk of fetus mortality in crash test simulations. In this paper, the effect of including the fetus in the uterus of the pregnant occupant model is investigated. First, isolated drop test simulations with the uterus of the computational pregnant occupant model, 'Expecting', with and without a fetus are used to show the effect of the presence of fetus in the uterus model. Then 'Expecting' with and without the fetus is used with varying levels of restraint system use, such as fully restrained, 'seatbelt only', 'airbag only' and 'no restraint', in frontal crash simulations, representing five levels of impacts. Maximum strains developed in the uteroplacental interface with and without a fetus are compared in every case. Both simulations predict higher risks of placental abruption when the fetus is included in the model. Simulations with and without a fetus model show that inclusion of a 38-week fetus model causes higher strains in the placental region of uterus.
\end{abstract}

\section{Introduction}

There are 131.5 million pregnancies in the world which conclude with birth every year. It has been shown that $6 \%-7 \%$ of all pregnancies are affected by trauma, with motor-vehicle accidents being the leading cause of accidental fetal mortality worldwide [5,8]. According to Department of Transport National Travel Survey [7], from 1997 to 2012 the average number of trips by women drivers has increased by $12 \%$ and average distance travelled has increased by $25 \%$.

During pregnancy, a woman's body changes significantly. Especially around the hip, abdominal and chest regions, a wide variety of physical changes occurs as detailed by Acar and Weekes [4]. Continuously changing anthropometry of pregnant women can create serious comfort and safety problems in motor vehicles which are normally designed for standard occupants. From this point of view, the transportation of pregnant occupants can be hazardous for the fetus.

The most common cause of fetal loss with known origins is placental abruption [9]. The injury occurs where the placenta becomes partially or completely detached from the inner surface of the uterus wall, the uteroplacental interface (UPI), disrupting the supply of oxygen and nutrients to the fetus. Strain levels at the UPI are taken as the indication of placental abruption leading to fatalities. Experimental data suggests that placenta detaches from the uterus when the strain level reaches 0.6 , which is taken as the threshold for fetus fatalities [14].

One way of assessing the safety of occupants in motor vehicle accidents is using anthropomorphic test devices (ATDs). The biofidelity of physical crash test dummies is limited. The only commercially available experimental pregnant crash test dummy is MAMA2B and no placenta or fetus is included in it. Its uterus is represented by a waterfilled bladder.

On the other hand, computational human body models could offer more detailed and realistic representation of the human body. Computational models have been increasingly used in crash simulation applications over the last decade. Finite element pregnant female models are developed to predict the safety of pregnant women and fetus in motor vehicle accidents. The computational pregnant occupant models usually include a finite element uterus and placenta but include no fetus as in Moorcroft et al. [12] or include a lump mass representing the fetus as in Delotte et al. [6]. None of these models incorporate detailed anthropometric changes of the whole body of pregnant women. 
'Expecting', the computational pregnant occupant model developed by Acar and van Lopik [1] at Lough- borough University, represents 38-week pregnant, 5th percentile female occupant. 'Expecting' includes a finite element uterus and placenta as well as a detailed multi- body fetus as detailed in Acar and van Lopik [2]. The model also incorporates anthropometric changes to the female body during pregnancy [3].

\section{Methodology}

In this investigation, two sets of simulations were con- ducted in order to demonstrate the difference between the strain levels at the UPI:

(1) Vertical drop test simulations of the isolated uterus model of 'Expecting' with and without the fetus;

(2) A set of crash simulations with 'Expecting' (with fetus) and a new version of 'Expecting' without a fetus.

\subsection{The pregnant occupant model: 'expecting'}

'Expecting', the computational pregnant occupant model, based on 5th percentile female MADYMO model, embodies the complexity of pregnant women's anatomy and anthropometric details using 49 measurements sets of data from 107 pregnant women volunteers [4]. The model is a hybrid multibody and finite element one. A finite element layer of fat encloses the outer surface of the finite element uterus with a placenta at the fundal position as this is the most common placental position [13]. The inner surface of the uterus using quad elements was meshed first, and then the elements were mapped to the outer surface to create the uterus. Then, the corresponding elements of the placental outer surface were mapped to the inner surface of the uterus to create the placental elements. The outer fat layer was also similarly created by mapping it to the outer surface of the uterus. The nodal coordinates and element configuration were then exported into MADYMO, where 8-noded solid elements were used for the finite element (FE) components.

The finite element uterus model was built in accordance with the fetus dimensions and configuration con- trolling the dimensions of the uterus to provide a snug fit around the fetus to represent the 38 weeks of pregnancy as shown in Figure 1(b). Thirty-eight weeks of gestation was selected because it was taken to represent a full term of pregnancy as the mass of fetus is at almost its maximum. Hence, the abdomen would be located closest to the steering wheel in the driving position. Earlier gestational ages, therefore, represent less severe cases. Furthermore, 5th percentile pregnant occupant, due to her stature having to sit closer to the steering wheel in order to reach the control pedals, represents the worst possible case.

A detailed multi-body representation of a fetus within the uterus was also integrated into the model [1]. During the later stages of pregnancy the fetus almost fills the entire volume of uterus but is free to move within the uterus during an impact, only con- strained by the boundaries of the uterus. A finite element fetus model would represent a more realistic deformable fetus and potentially may absorb some impact energy and thus the strains at the UPI may generally be lower. However, a detailed multi-body fetus model was preferred to a finite element model at this stage, due to scarcity of hard and soft tissue material properties of the fetus.

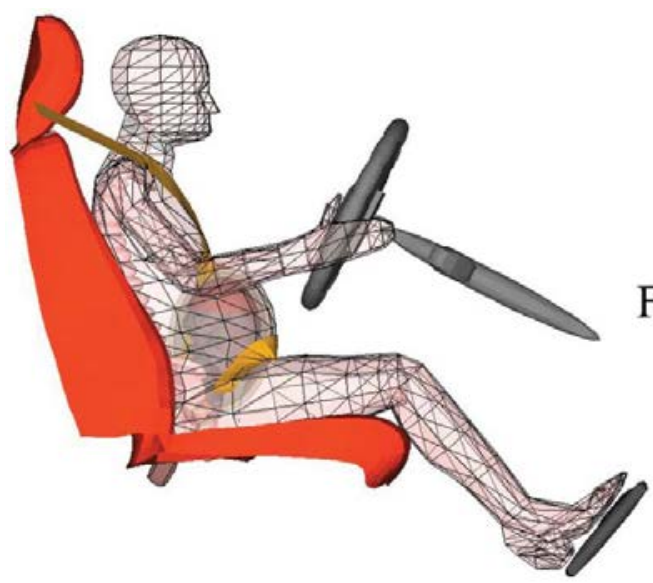

(a)

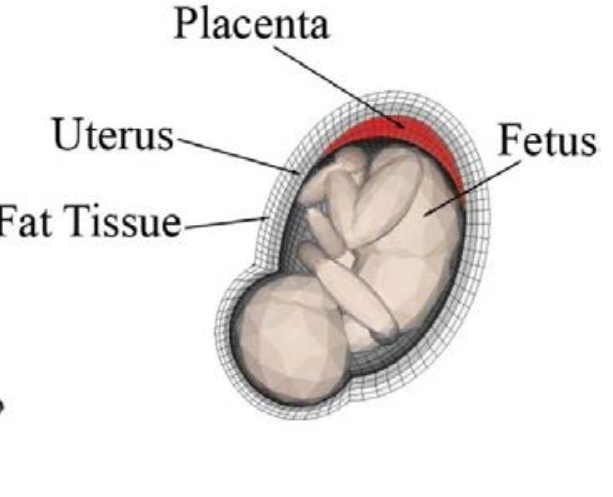

(b)

Figure 1. The pregnant occupant model ‘Expecting’(a); uterus, placenta and fetus in ‘Expecting’(b). 
The fetus model was composed of 15 rigid bodies representing various anatomical regions of the fetus which were interconnected by kinematic joints. The size of the 15 elements and the joint properties were based on the data found in the published literature as detailed in [2]. A total fetal mass was $3.3 \mathrm{~kg}$ and the resulting total mass of the uterus with the placenta and the fetus was nearly $4.6 \mathrm{~kg}$.

A without-fetus version of 'Expecting' was also generated, in that the entire uterus is filled with the amniotic fluid, which is $98 \%-99 \%$ water and hence can be considered as incompressible [2]. The magnitude and location of the forces exerted by the solid fetus and the consequent stresses and strains at the UPI were com- pared to those exerted by the amniotic fluid.

In 'Expecting' the 38 weeks old fetus almost filled the entire volume of the uterus leaving minimal space for the amniotic fluid. The effect of the small amount of fluid that surrounds the fetus was assumed to be negligible (less than $10 \%$ of the uterus volume) compared to the size of the fetus. The material properties of the uterus, placenta, fat tissue and amniotic fluid, as taken from the literature, were detailed in [1].

The abdomen of the pregnant occupant model 'Expecting' was validated against abdominal impact to rigid-bar and seatbelt loading tests as detailed by Hardy et al [10]. Further details of validation of the model can be found in [1].

The 'Expecting' model was placed within a typical vehicle interior model, consisting of a seat, vehicle floor, pedals, bolsters and steering wheel [1] as shown in Figure 1(a), in the multibody/finite-element software package MADYMO [11]. The model represented a driver which was chosen over the occupant model to be able to include the effect of impacting steering wheel, as well as the airbag, on the uterus.

\subsection{Vertical drop tests with and without fetus}

A study by Rupp et al. [14] simulated vertical drops of a uterus model, containing a simplified fetus geometry represented by two ellipsoids, representing an earlier gestational age than 'Expecting', onto a rigid flat surface from $0.5 \mathrm{~m}$ at angles of $0^{\circ}, 30^{\circ}$ and $90^{\circ}$. This work concluded that 'the contribution of the fetus to the stress and strain generated in the UPI is probably small relative to the strain caused by deformation of the uterine wall' and 'an A-P compression, which would be commonly seen in a frontal impact, or inertial loading of the uterus, will not tend to cause fetal loading of the placenta'.

Rupp et al. conducted further drop tests without the lumped mass representing the fetus to investigate the effect of the pressure gradient caused by the inertia of the amniotic fluid and the effect of an impactor bar on the uterus, not too dissimilar to the impact of the steering wheel. They concluded that the pressure gradient could cause high strain rates at the posterior region of the uterus with minor effect on the placenta, which is normally placed at the fundus position. They also concluded that the peak uterine strains, when impacted by a bar, reached levels greater than 0.60 and hence direct loading in the region of the placenta could have the potential to cause placental abruption. This is analogous to the potential impact of a steering wheel which is likely to impact the region of the placenta.

However, their overall conclusion that it was not necessary to include physical representations of the fetus or placenta in the model is debatable because the inertial effect of the solid fetus, compared to the amniotic fluid only, especially at the later stages of the pregnancy, is likely to change the dynamics loading on the uterine walls.

This study, therefore, replicates the drop tests reported in [14] using the uterus model of 'Expecting' with and without the fetus, to compare the effect of including the fetus on the UPI strain levels. With-fetus and without-fetus versions of FE uterus models were dropped vertically onto a rigid flat surface from $0.5 \mathrm{~m}$ height, at angles of $0^{\circ}, 30^{\circ}, 90^{\circ}$ and $180^{\circ}$ in order to investigate the effect of the fetus on the strains on uterus. Figure 2 shows the vertical drop test of both models at $0^{\circ}$ orientation. Figure 3 shows the withfetus model at angles of $0^{\circ}, 30^{\circ}, 90^{\circ}$ and $180^{\circ}$. The maximum strains on uterus with and without fetus cases were determined.

\subsection{Frontal crash simulations with and without fetus}

In addition to the drop tests of uterus with and without the fetus, the research strategy used in this part of the study was to use the pregnant occupant model 'Expecting' with and without the fetus (Figure 4). Four different restraint scenarios at a number of crash severities were used to determine the maximum strain levels anywhere in the uterus and at the placental location in order to compare the effect of inclusion of a fetus on the placental abruption risk.

Simulations included (a) 'seatbelt and airbag', representing an appropriately restrained pregnant driver; (b) 'seatbelt only' excluded the airbag; (c) 'airbag only' excluded the seatbelt, but yet the airbag was active; and finally (d) 'no restraint' excluded all restraints, in other words neither the seat belt was worn nor was the airbag deployed. For each case, tests were run with crash speeds of 15, 20, 25, 30 and $35 \mathrm{kph}$, and the acceleration pulses applied to the model were half-sine waves with 120 ms duration (Figure 5). 

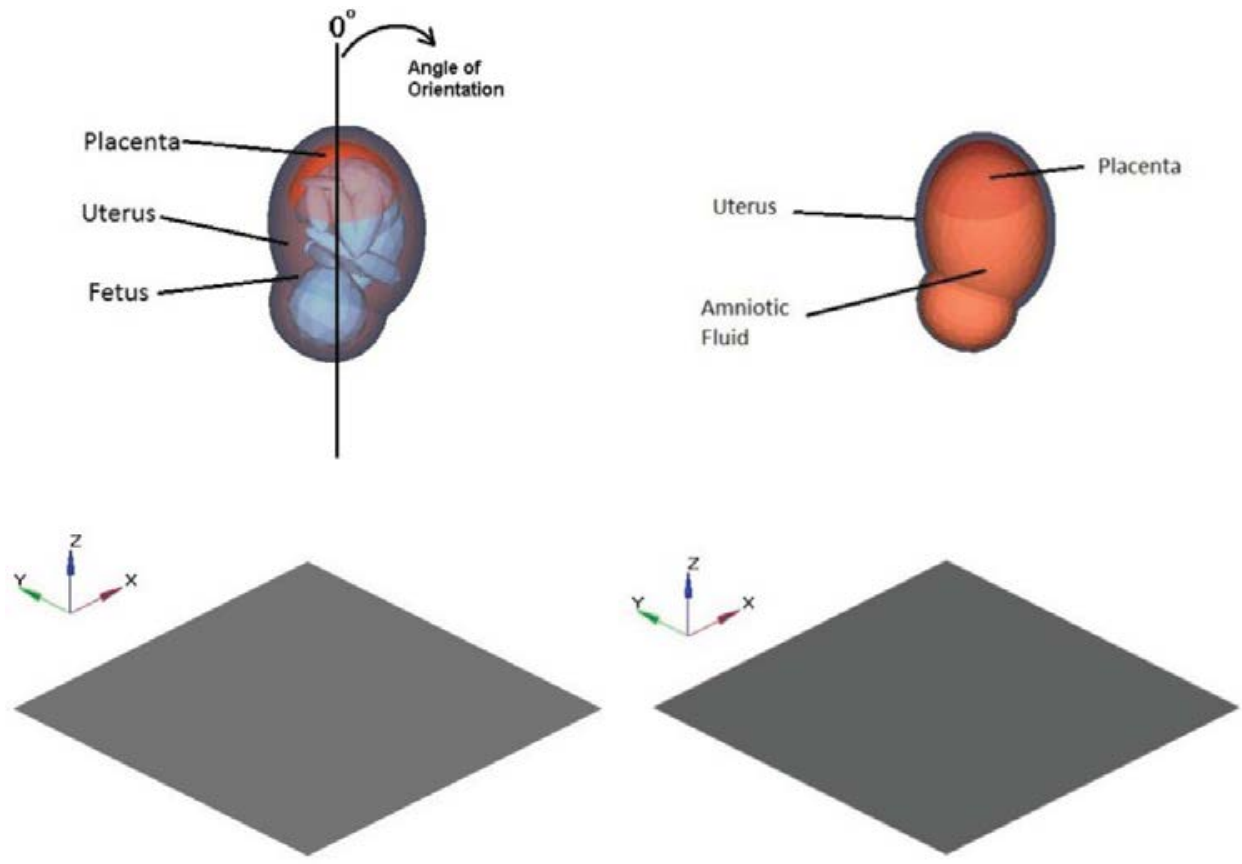

Figure 2. Drop tests with and without fetus at $0^{0}$ orientation.

Maximum von Mises equivalent strain levels in the uterus were determined for with-fetus and without-fetus models to assess the possibility of placental abruption, which is the main cause of fetal and occasionally maternal fatalities. The threshold strain value of widely accepted 0.60 is taken for the occurrence of placental abruption at the UPI leading to fetus mortality [14].
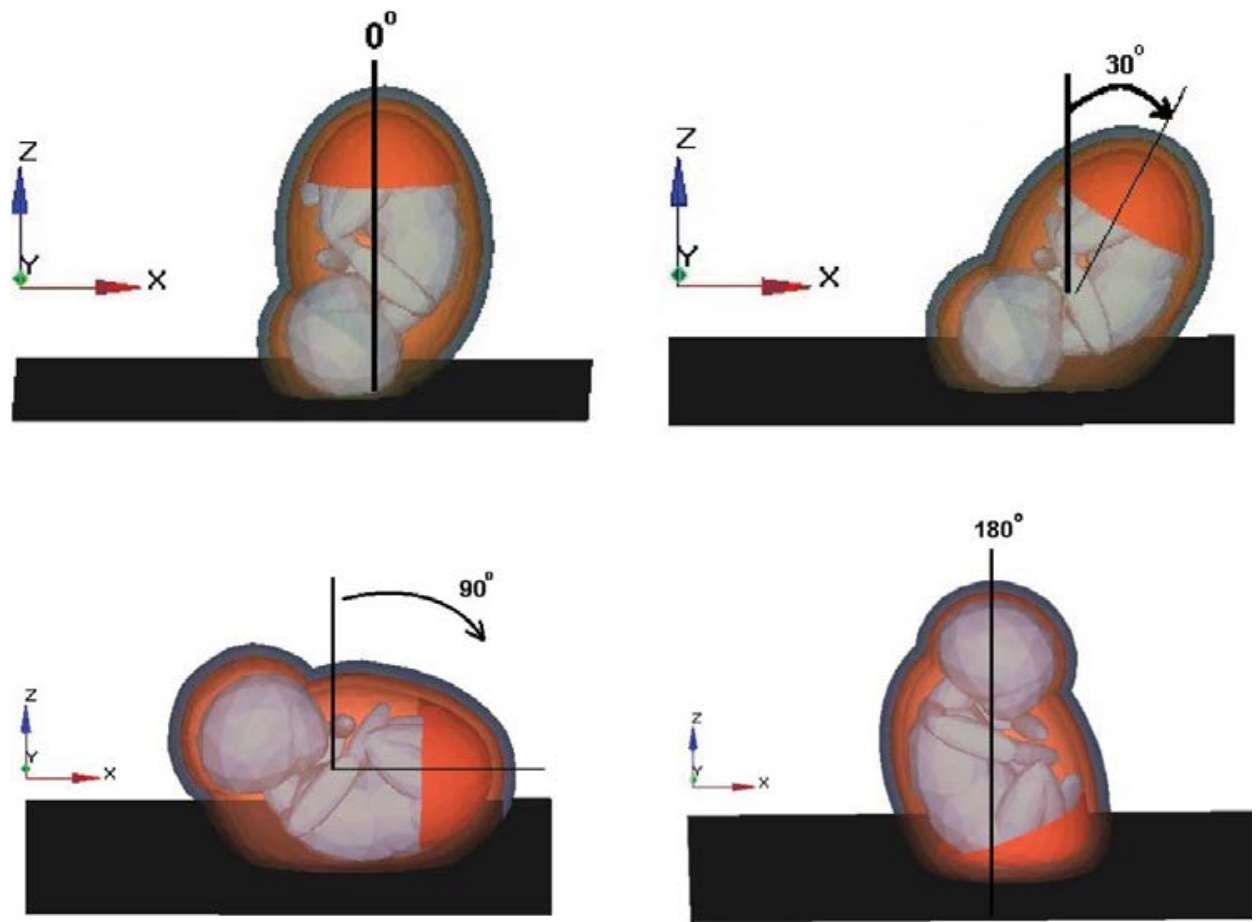

Figure 3. Drop tests with fetusat $0^{\circ}, 30^{\circ}, 90^{\circ}$ and $180^{\circ}$ orientation. 

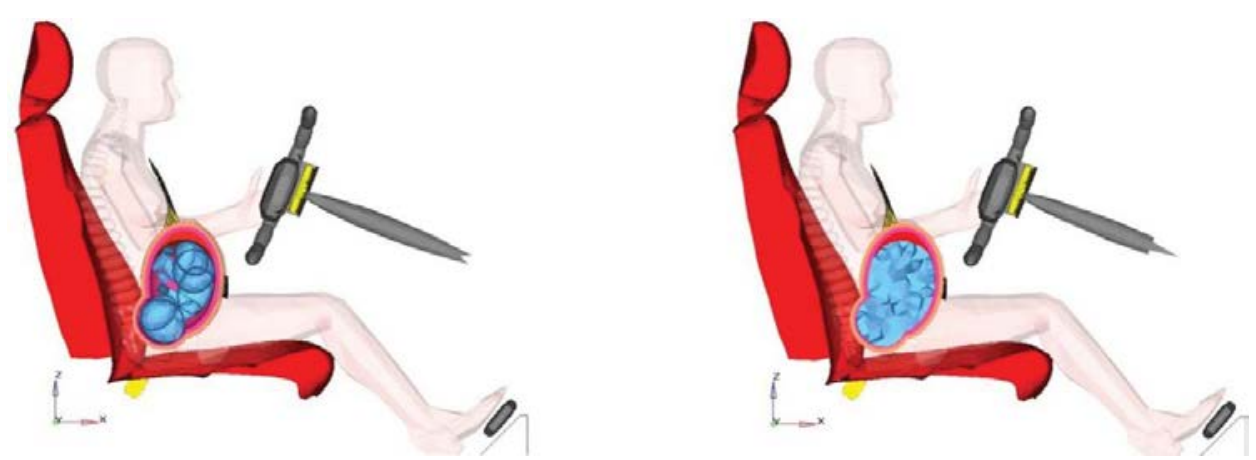

Figure 4. Computational pregnant occupant model ‘Expecting’ (with fetus) and modified ‘Expecting’ without a fetus.

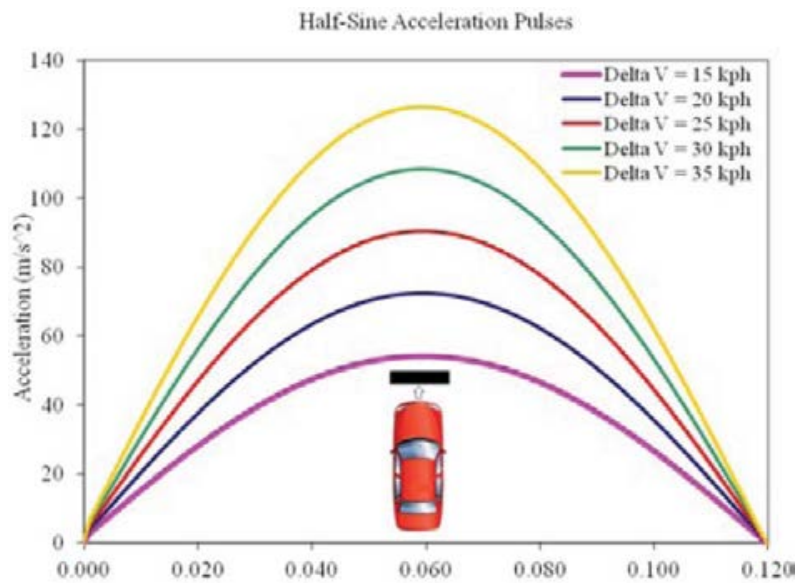

Figure 5. Acceleration pulses used as input for the crash simulations.

In general, the maximum Von Mises strain in the uterus with the fetus is significantly higher than without the fetus model, including the strain at UPI (Table 1).

At the angle of $0^{\circ}$ orientation (Figure 6) the uterus model with the fetus exceeds the threshold when the model hits the impact plane, due to the compression of the uterus wall between the head of the fetus and impact surface. Without the fetus model, the highest strain is observed about the contact surface of the uterus with rigid floor and is much lower than the strain levels of the with-fetus model. Strain levels at UPI are almost negligible for both cases.

$30^{\circ}$ orientation drop test simulations show similar results, generally with higher strain levels than the $0^{\circ}$ orientation. For the $90^{\circ}$ orientation angle, the maximum strain values in the uterus are very similar for with-fetus and without-fetus cases.
In the $180^{\circ}$ orientation, however, the placenta is at the leading end of the uterus in the drop test simulations (Figure 7), hence, compressed between the fetus and the impact surface. The maximum strain on the uterus therefore occurs at the UPI, resulting a very high strain value of 2.57 . In the model without the fetus, a much lower strain value of 0.66 is observed. The results clearly show that the fetus causes a sharp rise in the strain level when the utero-placental region is impacted directly causing the placenta to be compressed between the fetus and the external impact surface. This is not too dissimilar to the impact of the steering wheel or the air-bag on the uterus.

\subsection{Frontal crash simulations}

Crash test simulations also show that, in general, the maximum strains in the with-fetus model are found to be typically higher than the maximum strains in the without-fetus model, indicating a greater risk of placental abruption. Figure 8(a) and (b) visually depicts a typical impact response at 30 kph for the fully restrained pregnant driver model with and without the fetus, respectively.

Figure 9(a) compares the strain levels for the fully restrained case using the seatbelt and airbag for a crash speed range of 15-35 kph. The without-fetus model simulation results show lower strain levels than with-fetus model simulations up to the $35 \mathrm{kph}$. Figure 9(a) shows that maximum strains at the UPI for the with- and without-fetus models vary between $0.24-0.42$ and $0.18-0.42$, respectively. The increase for without fetus case is gradual and almost linear, whereas for the with fetus case, there is a greater increase in strain from 15 to $20 \mathrm{kph}$. All strain values at the UPI are considerably below the injury threshold value of 0.60 .

Table 1. Von Mises strain levels at UPI with and without fetus drop tests.

\begin{tabular}{|c|c|c|c|c|c|c|c|c|}
\hline \multirow[b]{2}{*}{ Droptest } & \multicolumn{2}{|c|}{$0^{\circ}$} & \multicolumn{2}{|c|}{$30^{\circ}$} & \multicolumn{2}{|c|}{$90^{\circ}$} & \multicolumn{2}{|c|}{$180^{\circ}$} \\
\hline & Whole uterus & UPI & Whole uterus & UPI & Whole uterus & $\overline{\text { UPI }}$ & Whole uterus & UPI \\
\hline Withfetus & 1.37 & 0.07 & 2.02 & 0.17 & 0.89 & 0.30 & 2.57 & 2.57 \\
\hline Without fetus & 0.72 & 0.01 & 0.66 & 0.02 & 0.86 & 0.24 & 0.66 & 0.66 \\
\hline
\end{tabular}



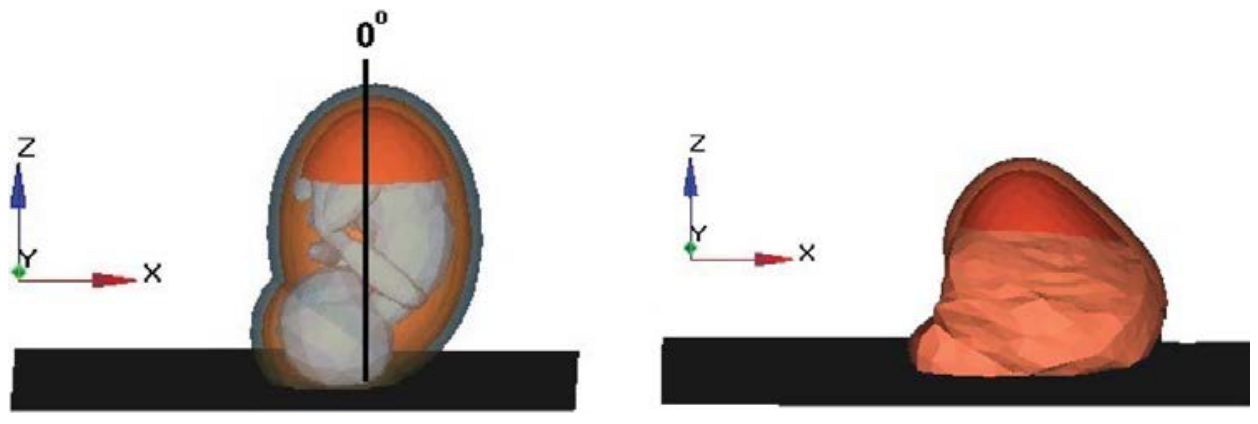

Figure 6. Vertical drop tests of the uterus with fetus and without fetus at angle of $0^{\circ}$ orientation.
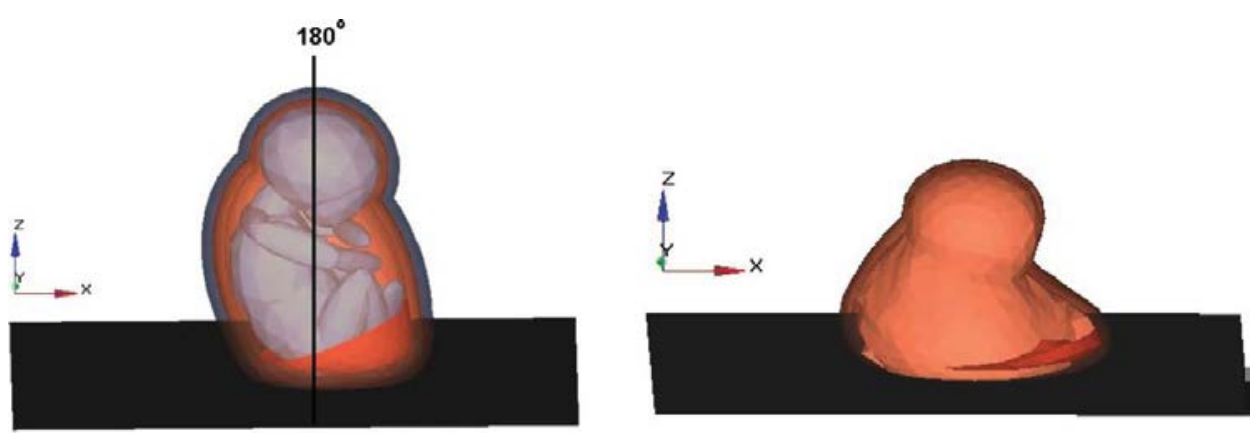

Figure 7. Verticaldroptests of the uterus with fetus and without fetus at angle of $180^{\circ}$ orientation.

The maximum strains at the UPI for the 'seatbelt only' case are shown in Figure 9(b), which follows a similar pattern to the strains in the 'seatbelt and airbag' case, but are generally higher. At 35-kph impact, the strain level approaches the placental abruption risk threshold of 0.60

for both cases. The higher strain levels could be attributed to the pressure that the steering wheel applies to the uterus at the anterior edge of the placental location forcing the fetus downwards. However, the lap portion of the three-point seatbelt prevents the occupant moving excessively forward. The placenta and uterus are also com- pressed between the fetus and steering wheel in the with- fetus model and this generates considerably higher strains at the UPI than in the without-fetus model.
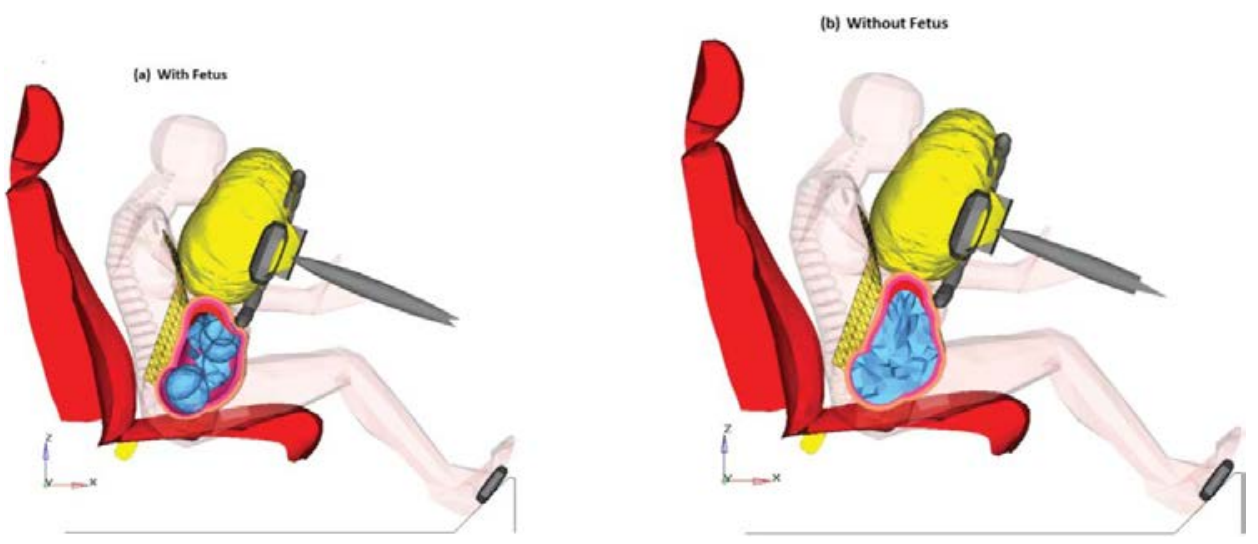

Figure 8. Typical frontal impact responses for $30 \mathrm{kph}$ at $105 \mathrm{~ms}$ of impact. 
Seat Belt \& Airbag

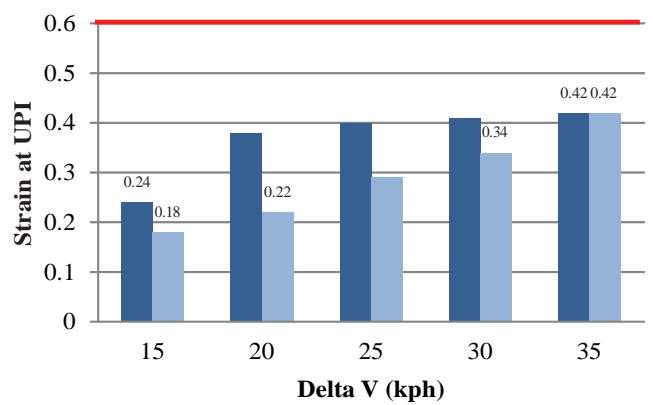

(a)

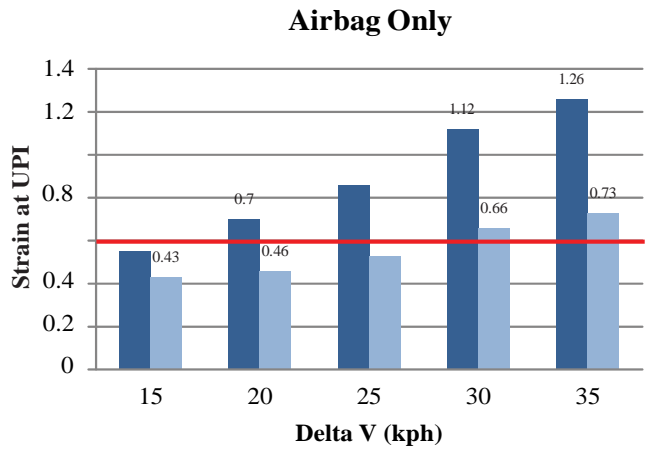

(c)

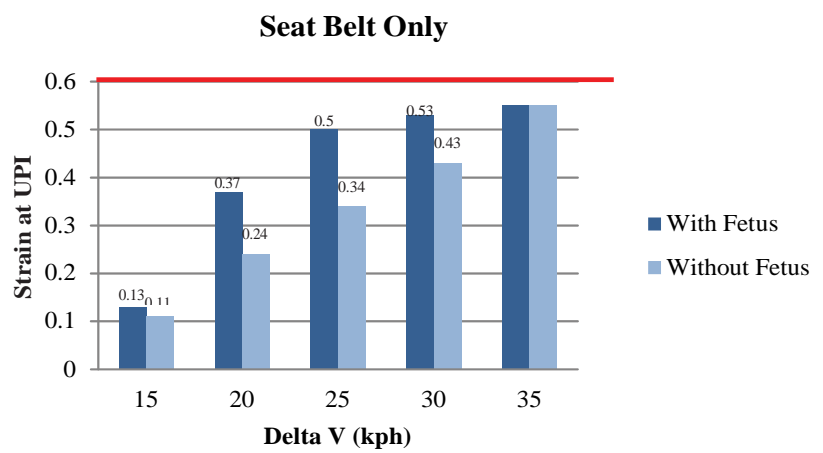

(b)

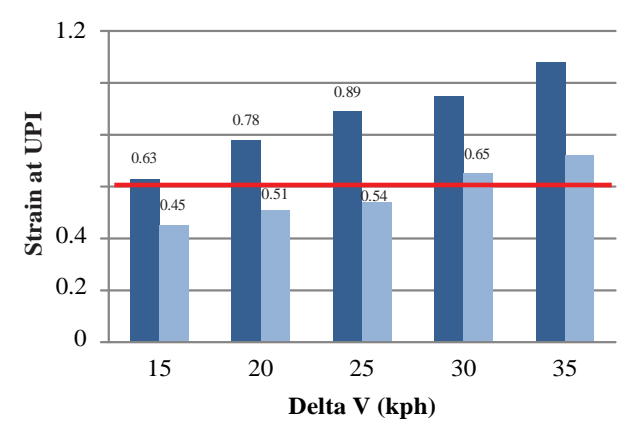

(d)

Figure 9. Strain levels at UPI for four restraint cases and five crash speed. (a) Fully restraint (seatbelt and airbag) case. (b) Seatbelt only case. (c) Airbag only case. (d) No restraint case.

Figure 9(c) shows the maximum strain levels at the UPI for the 'airbag only' case exceeds the strain threshold at $20 \mathrm{kph}$ when the fetus is included in the model. The placental abruption risk emerges at this speed, whereas the without-fetus model shows that the placental abruption risk begins at a higher crash speed of $30 \mathrm{kph}$. Without the seatbelt, it is clear that the contribution of the fetus to the maximum strains at the UPI is much more pronounced and the placental abruption risk is found to be much higher.

For the 'no-restraint' case shown in Figure 9(d), the with-fetus model shows placental abruption risk at all speeds considered (15-35 kph), whereas the without- fetus model depicts strains at the UPI below the placental abruption threshold value of 0.60 for the 15, 20 and $25 \mathrm{kph}$ simulations.

\section{Discussion}

In this paper, implications of including a fetus in the uterus of 'Expecting' pregnant woman model against the amniotic fluid only model have been reported. First, vertical drops onto a rigid flat horizontal surface at angle of orientation of $0^{\circ}, 30^{\circ}$, $90^{\circ}$ and $180^{\circ}$ were simulated for the isolated uterus model with and without the fetus to imitate the simulations reported by Rupp et al [14]. How- ever, as the fetus model used in this study represents a later gestation age than the one reported by Rupp et al. and it is more detailed consisting of 15 jointed bodies, a direct comparison with their findings is not intended.

Furthermore, the complete computational pregnant occupant model 'Expecting' (with fetus) and its with- out-fetus, amniotic fluid only version were used to simulate a range of frontal impacts of increasing severity from 15 to $35 \mathrm{kph}$. Four cases of occupant restraint scenarios, namely seat belt and airbag, seat belt only, airbag only and completely unrestrained were considered. Maximum von Mises strains at the UPI, which is a measure of determining whether the placental abruption occurs, were established for both with and without fetus cases to determine the effect of inclusion of a fetus.

Both the drop-test and crash-test simulation results suggest that the inclusion of the fetus has a significant effect on the strain levels in the uterus. In all cases, the maximum strain levels are higher with the fetus than without the fetus model. This is attributed to the dynamic behaviour of the solid fetus which is surmised to be fundamentally different to that of the amniotic fluid. Both the fetus and amniotic fluid may have very similar densities and the total mass filling the uterus would be similar in both cases. However, it is argued that the type of mass rather than the quantity of mass plays a significant role in causing 
the stresses and strain in the uterus as a fetus, a solid mass, would dynamically behave differently to the amniotic fluid.

When a frontal impact occurs, the laws of dynamics dictate that the fetus continues to move forward inside the uterus causing inertial loading on the anterior region of the uterus, hence stretching the uterine wall, creating local pressures as it is restrained only by the elastic wall of the uterus, whereas a fluid would more evenly distribute the load. Crash test simulations also show that the inclusion of the fetus would also cause the strain levels to increase when the pregnant women's abdomen impacts with the steering wheel and/or the airbag as the forward travelling fetus compresses the uterus against them.

\section{Conclusions}

It can be concluded that the inclusion of a 38-week fetus in the uterus changes the dynamic response of the model compared to amniotic fluid only model in crash simulations, and has a significant effect on the loading of the uterus. It is therefore suggested that the fetus should be included in the uterus in pregnant occupant models for more realistic representation of the pregnant occupant in crash test simulations.

It is anticipated that a fully finite element fetus model would render the pregnant occupant model to be much more realistic and potentially may absorb some impact energy. This is planned for future development of 'Expecting'; however, it should be recognised that deter- mining the material properties of the soft tissue of fetus would pose a significant challenge.

\section{Acknowledgments}

The authors would like to thank the EPSRC (Engineering and Physical Sciences Research Council, UK) and Loughborough University IMCRC (Innovative Manufacturing and Construction Research Centre) for funding pregnant occupant model- ling research projects and MADYMO for educational rates. The authors would also like to thank Loughborough University for the PhD scholarship for M.Meric.

\section{Disclosure statement}

No potential conflict of interest was reported by the authors.

\section{References}

[1] B.S. Acar and D. van Lopik, Computational pregnant occupant model, 'Expecting', for crash simulations, Proc. IMechE D J. Automob. Eng. 223 (2009), pp. 891-902.

[2] B.S. Acar and D. van Lopik, Modelling the fetus for pregnant occupant safety, Proc. IMechE K J. Multibody Dyn. 226 (2012), pp. 197-205.

[3] B.S. Acar, D. van Lopik, and A.M. Weekes, 'Expecting': occupant model incorporating anthropometric details of pregnant women, Int. J. Vehicle Des. 51 (2009), pp. 374-385.

[4] B.S. Acar and A. Weekes, Measurements for pregnant occupant safety, Int. J. Vehicle Des., 42 (2006), pp. 101-118.

[5] CEMD, Confidential enquiry into maternal deaths report, Department of Health, London, UK, 1999.

[6] J. Delotte, M. Behr, P. Baque, A. Bourgeon, F. Peretti, and C. Brunet, Modelling the pregnant woman in driving position, Surg. Radiol. Anat. 28 (2006), pp. 359-263.

[7] Department for Transport. National Travel Survey 2012 Statistical Release, Gov.uk, London, 2013.

[8] D. El-Kady, W.M. Gilbert, J. Anderson, B. Danielsen, D. Towner, and L.H. Smith, Trauma during pregnancy: an analysis of maternal and fetal outcomes in a large population, Am. J. Obstet. Gynecol. 190 (2004), pp. 1661-1668.

[9] J. Fildes, L. Reed, N. Jones, M. Martin, and J. Barrett, Trauma: the leading cause of maternal death, J. Trauma 32 (1992), pp. 643-645.

[10] W.N. Hardy, L.W. Schneider, and S.W. Rouhana, Abdominal impact response to rigid-bar, seatbelt, and airbag loading, Stapp. Car. Crash J. 45 (2001), pp. 132.

[11] MADYMO Manual, TNO Automotive BV, Delft, the Netherlands, 2003.

[12] D. Moorcroft, S. Duma, J. Stitzel, and G. Duma, A finite element and multi-body model of the pregnant female occupant for the analysis of restraint effectiveness, SAE Paper 2003-01-0157, Society of Automotive Engineers, 2003.

[13] R.J. Pepperell, E. Rubenstein, and I.A. MacIsaac, Motor- car accidents during pregnancy, Med. J. Aus., 1 (1977), pp. 203-205.

[14] J.D. Rupp, L.W. Schneider, K.D. Klinich, S. Moss, J. Zhou, and M.D. Pearlman, Design, development, and testing of a new pregnant abdomen for the Hybrid III small female crash test dummy”, Report UMTRI-2001- 07, University of Michigan Transportation Research Institute, Ann Arbor, MI, USA, 2001. 